\title{
Foam plombage: a novel technique for optimal fixation of polyglycolic acid sheets positioned using "clip and pull" after esophageal endoscopic submucosal dissection
}

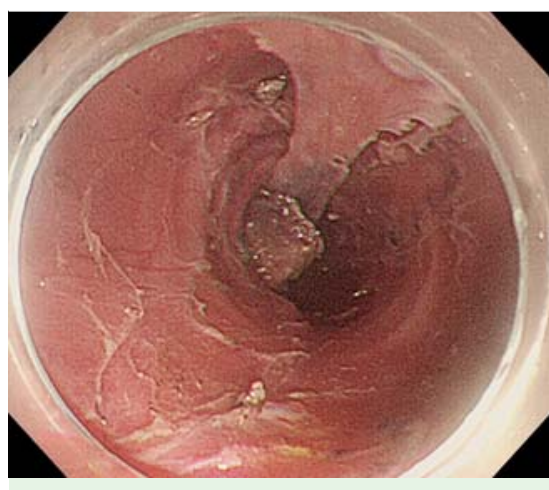

Fig. 1 Endoscopic view after en bloc endoscopic submucosal dissection (ESD) had been performed on two neighboring lesions leaving an artificial ulcer that extended for more than three-quarters of the esophageal circumference.

Shielding the artificial ulcer that is left after endoscopic submucosal dissection (ESD) with a polyglycolic acid (PGA) sheet is a promising method to prevent postoperative complications such as bleeding, perforation, and postoperative stricture, especially in the esophagus [1-4]. The clip and pull method has enabled us to deliver a single undivided PGA sheet that is large enough to completely shield the artificial ulcer [5]; however, ensuring correct adhesion of the PGA sheet is technically demanding. In this report, we introduce plombage with foam as an effective and reproducible method for fixing the PGA sheet after esophageal ESD.

A 73-year-old patient, after giving written informed consent, underwent esophageal ESD for two neighboring lesions in the mid-thoracic esophagus. After resection of the lesions in an en bloc fashion, the artificial ulcer was over three-quarters of the esophageal circumference, indicating a high risk of postoperative stricture ( $\bullet$ Fig. 1). Therefore, we elected to shield the artificial ulcer with a PGA sheet to prevent postoperative stricture.

After delivery and deployment of a PGA sheet moistened with a fibrin preparation using the clip and pull method, we sprayed a thrombin preparation onto the PGA

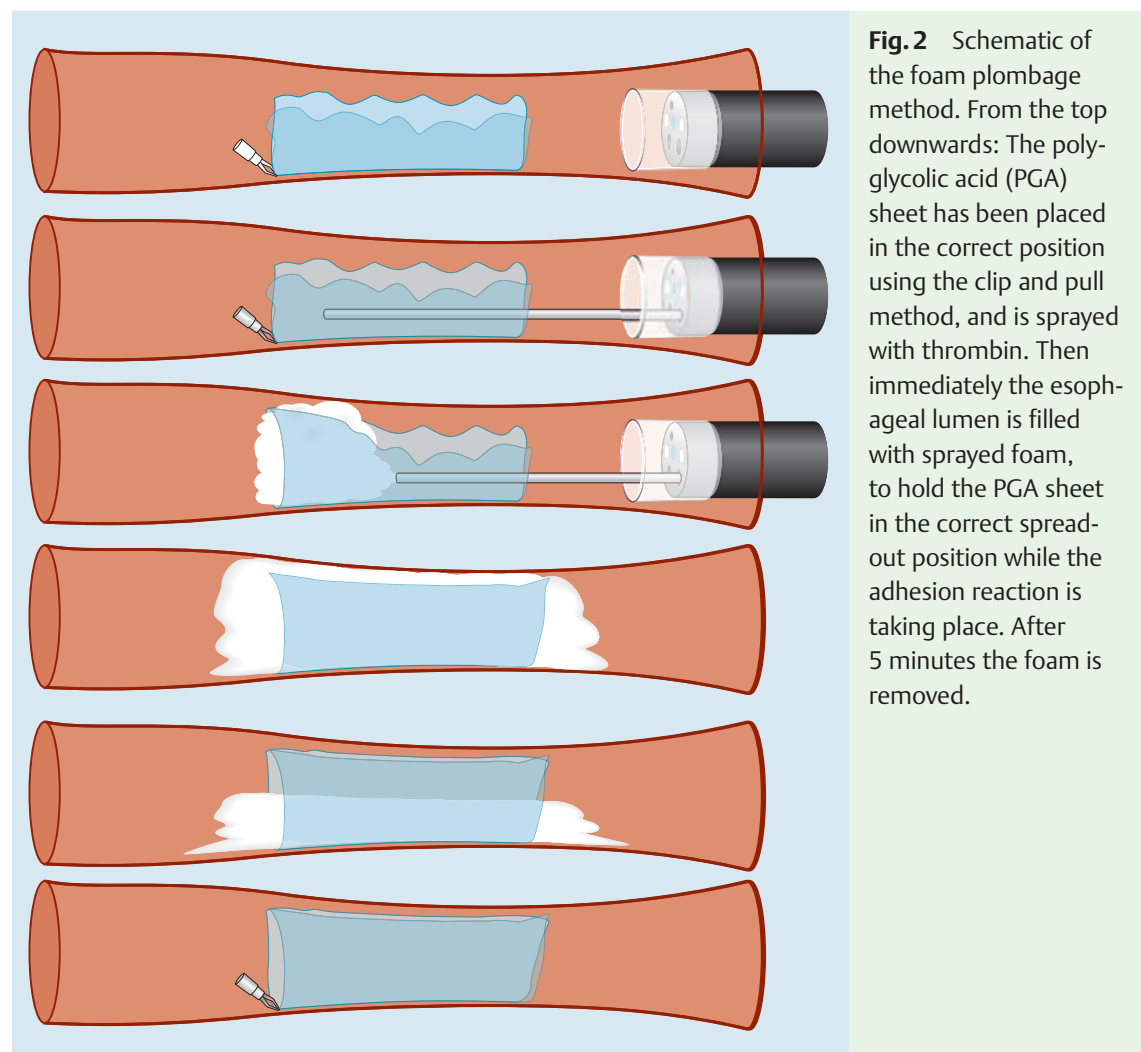

sheet to start the reaction of the fibrin glue. Immediately after spraying the thrombin preparation, we filled the esophageal lumen with approximately $20 \mathrm{~mL}$ of foam through a tube sheath (otherwise used with a ligation device, HX-20U-1; Olympus Medical Systems Corp., Tokyo, Japan) inserted through the scope ( $\bullet$ Fig. 2 ). Canned spraying cream (Sahne Wunder; Hochwald Food GmbH, Thalfang, Denmark), which uses nitrogen monoxide gas and is commercially available as food, was applied as the foam ( $\bullet$ Fig.3; $\bullet$ Video 1 ). Subsequently, we removed the foam 5 minutes after it had been applied and confirmed that the PGA sheet had adhered tightly to the artificial ulcer ( $\bullet$ Fig. 4 ).

The patient recovered well with no complications or symptoms of a stricture after 4 weeks' follow-up. This method was effective in spreading the PGA sheet radially and for a short time.

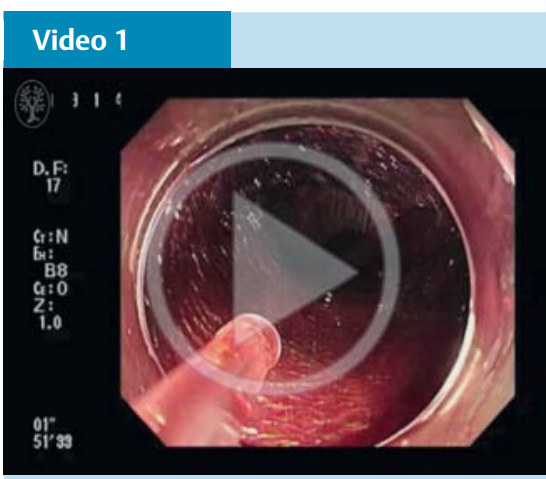

Use of foam plombage after the clip and pull method for application of a polyglycolic acid (PGA) sheet to an artificial esophageal ulcer. 


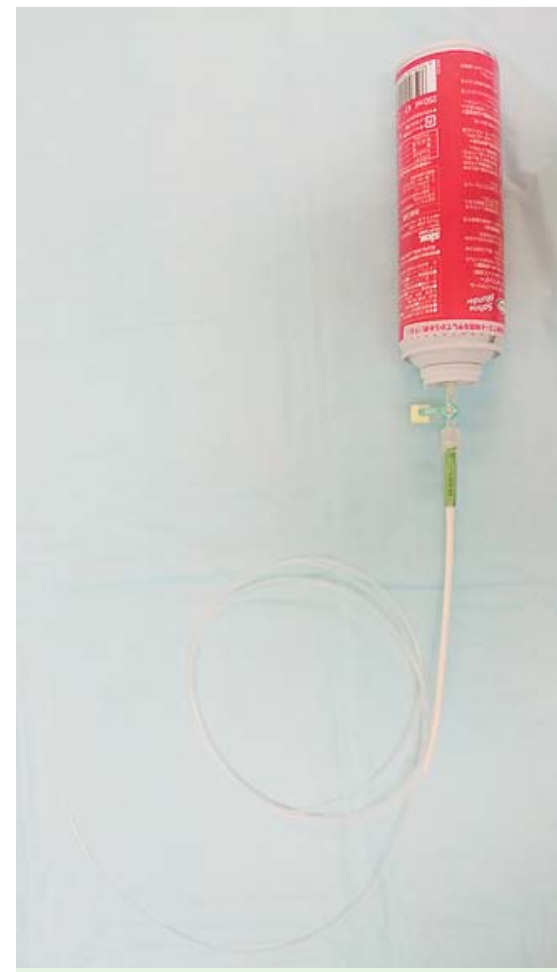

Fig. 3 The delivery system for the foam consisting of the tube sheath from a ligation device and the can of spraying cream.

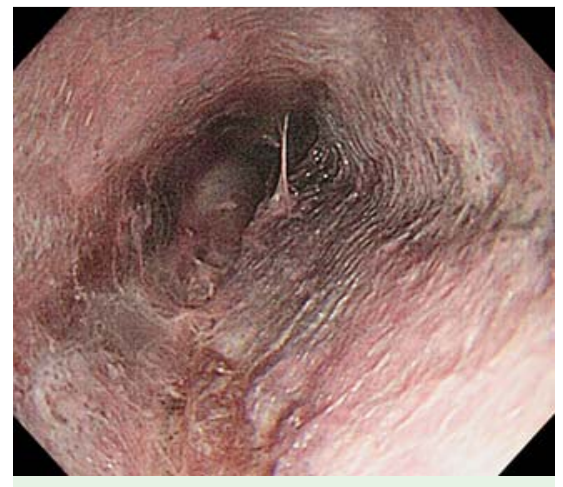

Fig.4 Endoscopic view after removal of the foam showing the polyglycolic acid (PGA) sheet in position and tightly adherent to the artificial ulcer.

\section{Endoscopy_UCTN_Code_TTT_1AO_2AI}

Competing interests: None

\section{Satoshi Ono ${ }^{1}$, Yoshiki Sakaguchi ${ }^{1}$, Yosuke Tsuji ${ }^{1,2}$, Shinya Kodashima', Nobutake Yamamichi' ${ }^{1}$, Mitsuhiro Fujishiro $^{1,2}$, Kazuhiko Koike ${ }^{1}$}

${ }^{1}$ Department of Gastroenterology, Graduate School of Medicine, The University of Tokyo, Tokyo, Japan ${ }^{2}$ Department of Endoscopy and Endoscopic Surgery, Graduate School of Medicine, The University of Tokyo, Tokyo, Japan

\section{References}

1 Takimoto K, Toyonaga T, Matsuyama K. Endoscopic tissue shielding to prevent delayed perforation associated with endoscopic submucosal dissection for duodenal neoplasms. Endoscopy 2012; 44 (Suppl. 02): E414E415

2 Tsuji Y, Fujishiro M, Kodashima S et al. Polyglycolic acid sheets and fibrin glue decrease the risk of bleeding after endoscopic submucosal dissection of gastric neoplasms (with video). Gastrointest Endosc 2015; 81: 906 912

3 Sakaguchi Y, Tsuji Y, Ono S et al. Polyglycolic acid sheets with fibrin glue can prevent esophageal stricture after endoscopic submucosal dissection. Endoscopy 2015; 47: $336-340$

4 Iizuka T, Kikuchi D, Yamada A et al. Polyglycolic acid sheet application to prevent esophageal stricture after endoscopic submucosal dissection for esophageal squamous cell carcinoma. Endoscopy 2015; 47: $341-344$

5 Ono S, Tsuji Y, Fujishiro $M$ et al. An effective technique for delivery of polyglycolic acid sheet after endoscopic submucosal dissection of the esophagus: the clip and pull method. Endoscopy 2014; 46 (Suppl. 01): E44-E45

\section{Bibliography}

Dol http://dx.doi.org/

10.1055/s-0034-1392612

Endoscopy 2015; 47: E435-E436

(c) Georg Thieme Verlag KG

Stuttgart · New York

ISSN 0013-726X

\section{Corresponding author \\ Satoshi Ono, MD, PhD}

Department of Gastroenterology

Graduate School of Medicine

The University of Tokyo

7-3-1 Hongo, Bunkyo-ku

Tokyo

Japan

Fax: +81-3-58008806

satoshi-tky@umin.ac.jp 